Article

\title{
Seepage Safety Assessment of Concrete Gravity Dam Based on Matter-Element Extension Model and FDA
}

\author{
Xiaoling Wang *, Hongling Yu, Peng Lv, Cheng Wang, Jun Zhang and Jia Yu \\ State Key Laboratory of Hydraulic Engineering Simulation and Safety, Tianjin University, Tianjin 300072, China; \\ yuhongling@tju.edu.cn (H.Y.); lvpeng0909@tju.edu.cn (P.L.); ChengWTJU@tju.edu.cn (C.W.); \\ zhangdajun@tju.edu.cn (J.Z.); yj1592533724@126.com (J.Y.) \\ * Correspondence: wangxl@tju.edu.cn; Tel.: +86-138-2180-8530
}

Received: 23 December 2018; Accepted: 1 February 2019; Published: 5 February 2019

\begin{abstract}
As an important infrastructure project, the concrete gravity dam plays an extremely important role in hydropower generation, irrigation, flood control, and other aspects. Seepage is an important factor affecting the stability of concrete gravity dams. Seepage safety assessment is of great significance to the safe operation of the dams. However, the existing seepage safety assessment models are not dynamic, and the correlation among indicators is often neglected and the overall seepage safety of the concrete gravity dams has not been considered. To solve these problems, this research proposes a dynamic matter-element extension (D-MEE) model. First, the D-MEE model is established through adroit integration of the matter-element extension (MEE) model and functional data analysis (FDA). Second, a dynamic criteria importance through the intercriteria correlation (D-CRITIC) method that can effectively consider the correlation among indicators is proposed to determine the weights. Third, the influence of different dam blocks on the overall seepage safety status is considered by constructing a spatial weight matrix. Finally, the proposed method is applied to the concrete gravity dam $\mathrm{X}$ in southwest China. The results show that the proposed method is effective and superior to the existing evaluation methods of seepage safety.
\end{abstract}

Keywords: seepage safety assessment; concrete gravity dam; matter-element extension model; FDA; D-CRITIC method; spatial weight matrix

\section{Introduction}

The problems of environmental pollution brought by conventional energy sources have posed great threats to the sustainable development of human beings [1]. Therefore, all countries are shifting to replace conventional energy sources with renewable energy. There are many kinds of renewable energy, such as hydropower, wind power, and solar power [2]. In addition to the advantages of low cost, continuous regeneration, and no pollution, hydropower development plays an active role in the comprehensive management and utilization of rivers. The Energy Development Strategic Action Plan (2014-2020) clearly states that by 2020, the total installed capacity of hydropower will reach 350,000 MW [3]. Therefore, hydropower is considered a promising renewable energy source [4].

Concrete gravity dams are made of concrete, which can resist various external forces by their own weight. They are an integral component of a society's infrastructure system and play an extremely important role in electricity generation, water supply, flood control, irrigation, and other purposes [5]. However, the safe operation of concrete gravity dams is affected by various factors such as deformation, seepage, strength, stability, and aging [6,7]. The adverse effect of seepage on the safe operation of gravity dam is mainly from the uplift pressure on the dam foundation surface, which is easily produced because of dam foundation seepage. The uplift pressure can decrease the anti-sliding force of the dam and threaten dam stability [8]. For example, the historical accident of Bouzey dam in 1895 was 
directly related to this phenomenon [9]. In addition, some roller-compacted concrete (RCC) gravity dams have also shown serious seepage problems, such as the Willow Creek RCC gravity dam in the USA and the Xibing RCC gravity dam in China [10]. Considering the adverse effects of seepage on the stability of concrete gravity dams, relevant codes and standards have been formulated from the aspects of dam design [11], monitoring [12], and evaluation [13]. In addition, relevant scholars have also conducted many researches on the seepage problems of concrete gravity dams. For example, Cheng [8] simulated the complex seepage field of a concrete gravity dam foundation based on the computational fluid dynamics (CFD) method, Zhu [14] proposed a fluid structure interaction (FSI) stochastic finite element approach to consider the influence of seepage on the reliability analysis of concrete gravity dam, and Jiang [15] employed a comprehensive investigation method to analyze the leakage problem of a concrete gravity dam with penetrating cracks. A new statistical model optimized with quantum genetic algorithm was utilized in Zhu's paper [16] to predict the concrete gravity dam's foundation uplift pressure under the function of highly influential typhoon.

In recent years, with the development of dam safety monitoring technology, the comprehensive evaluation models based on monitoring data have been established in many researches to evaluate the seepage safety status of the dam. The comprehensive evaluation methods of dam seepage safety mainly include the fuzzy comprehensive evaluation method [17], set pair analysis method [18], and matter-element extension model [19]. The fuzzy comprehensive evaluation method is a method based on the theory of fuzzy sets that was introduced in the 1960s [20]. It uses the membership degree to construct a fuzzy judgment matrix, and then classifies the grade according to the principle of maximum membership degree. It can solve the imprecision and fuzziness in classification criteria. However, the membership function is affected by subjective factors, and the accuracy of the result will be affected. Set Pair Analysis (SPA) is a method proposed by Zhao in 1989 to deal with the uncertainty problem [21]. The main principle of SPA is to analyze identity degree, discrepancy degree, and contrary degree by constructing the connection number [22]. Its calculation process is relatively simple, but the calculation of the connection number is rough, and it may lose a lot of useful information when determining the grades. The matter-element extension (MEE) model, proposed by Cai [23], does not need to determine the membership function, nor does it cause a lot of information loss in grade determination. The MEE model provides a qualitative and quantitative method to address contradictions and incompatibility problems through the transformation of the matter-element [24]. At present, in addition to the dam seepage, the MEE model has also been widely used in soil $[25,26]$, rock [27,28], concrete materials [29-31], regional water usage [32], power networking projects [33], and other fields. Although these methods play an important role in seepage safety assessment, there are still several problems that need to be solved:

(1) Dam seepage status is dynamically and continuously varied with time in nature, but most existing evaluation methods can only represent seepage safety status at finite discrete time points.

(2) Dam seepage is affected by various interrelated factors. However, the existing evaluation methods often ignore the correlation among indicators in the process of determining weights and the accuracy of the evaluation results needs improvement.

(3) A concrete gravity dam is composed of several dam blocks, which act against forces both independently and dependently of adjacent blocks. However, the existing evaluation methods often take a single dam block as the research object; the evaluation results cannot easily to reflect the overall seepage safety of the dam.

For the first problem, although the matter-element extension method is very popular and has been used in many fields, it is still a static assessment method that cannot easily characterize the dynamic variability of the evaluation objects. The current research on dynamic comprehensive assessment has achieved numerous results, such as the subjective and objective weighting method [34], dynamic fuzzy grey relational analysis method [35], variable fuzzy pattern recognition model [36], value function model [37], system dynamics method [38], and Bayesian method [39]. However, most of the assessment 
methods mentioned above can only assess the seepage safety status at discrete time points, and they find it difficult to represent the continuous variation process of the seepage safety status. In addition, they are not feasible if there are missing values or irregular sampling times. Functional data analysis (FDA) [40] has emerged as an effective approach to solve this problem. The main idea of FDA is to represent discrete monitoring data from a time series as a continuous function. In recent years, there are increasing research interests in employing and developing FDA [41-44]. Therefore, a dynamic matter-element extension (D-MEE) model was established by introducing the FDA method into the MEE model in this study.

For the second problem, the correlation among the indicators will make the indicator information overlap to some extent and will affect the accuracy of the evaluation results. There are two main methods to address the correlation among the indicators; one is principal component analysis (PCA) [45], and the other is criteria importance through intercriteria correlation (CRITIC) method [46]. PCA is a dimension reduction method in multivariate statistics [47,48]. The CRITIC method is often used to determine the objective weights of the indicators [49-53]. It assigns weights according to the contrast intensity of indicators and the conflicts among them. Compared to PCA, CRITIC is considered to be less computationally challenging [46]. However, CRITIC is a static method that cannot reflect the dynamic change of the importance of indicators. Therefore, a dynamic CRITIC (D-CRITIC) method based on FDA is proposed in the process of determining the weights of the indicators.

For the third problem, the spatial weight matrix provides a good tool for considering the impact of different dam blocks on overall seepage safety. The spatial weight matrix [54-56] reflects the magnitude of the influence between adjacent regions. Adjacency-based spatial weight is one of the most common forms of constructing the spatial weight matrix [57-60]. In adjacency-based spatial weight, the closer the two regions are, the stronger the correlation and vice versa. Figure 1 can briefly illustrate adjacency-based spatial weight. It can be seen from Figure 1 that the corresponding element in the spatial weight matrix is set to 1 when two regions are adjacent (having common boundaries or vertices); otherwise, it is set to 0 . The resulting adjacency-based spatial weight matrix is symmetric, which indicates that the interaction between the two regions is consistent. However, the interaction among different evaluation regions is often asymmetric. To overcome this deficiency and improve the robustness of the evaluation results, some studies have introduced internal factors including migration flows, wage, and price to the construction of spatial weight matrix [61-63]. These studies have achieved good performance in practical applications. Thus, the evaluation eigenvalue of each dam block is proposed as an internal factor and is integrated into the adjacency-based spatial weight matrix to obtain the comprehensive score and safety level for the overall seepage safety of the dam.

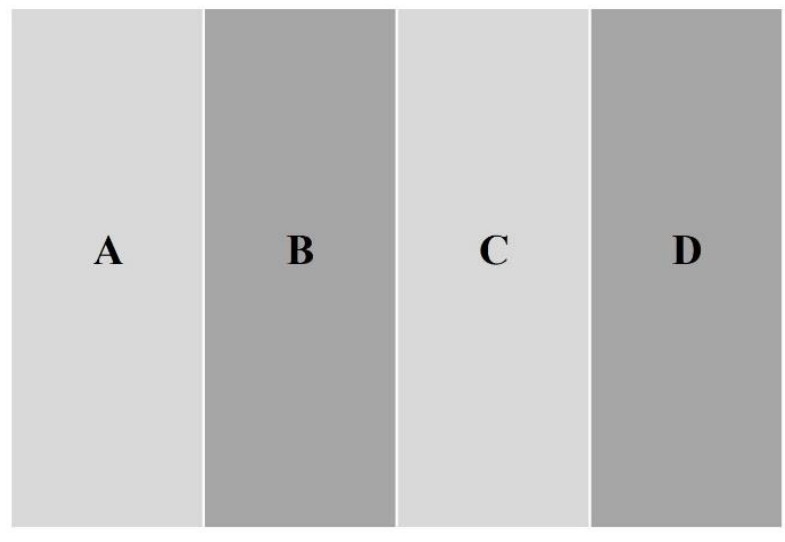

(a) Regional map

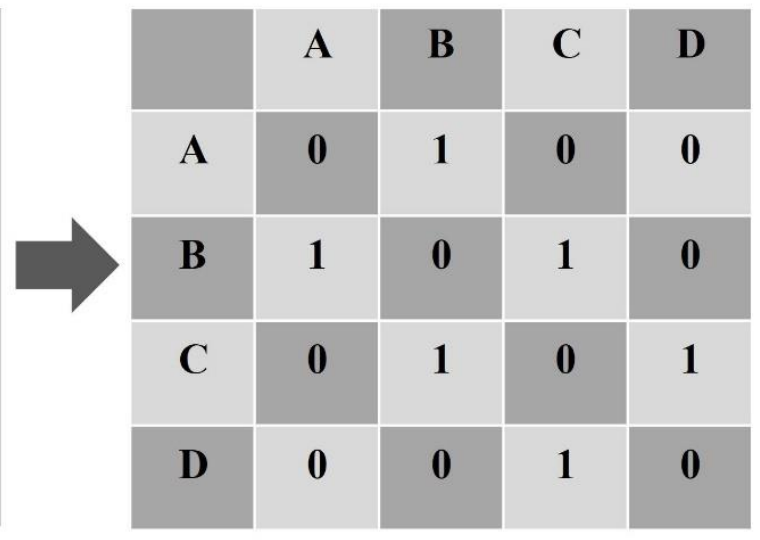

(b) Spatial weight matrix

Figure 1. Schematic plot of the spatial weight matrix. 
The purpose of this study is to dynamically and comprehensively assess the overall seepage safety of a concrete gravity dam. Therefore, the work of this study mainly focuses on the following three goals.

(1) Establish the D-MEE model based on the MEE model and FDA.

(2) Propose the D-CRITIC method to determine the weights of the indicators.

(3) Construct the spatial weight matrix and assess the overall seepage safety.

The remainder of this paper is organized as follows. Section 2 is devoted to provide the methodology of this study, the indicator system is established based on the PSR framework, the D-MEE model is proposed based on the MEE model and FDA, in which the D-CRITIC method considers the correlation among indicators, and the spatial weight matrix is constructed to assess the overall seepage safety. Furthermore, the application of the proposed method to a concrete gravity dam $\mathrm{X}$ in China is presented in Section 3. Finally, the discussion and conclusion are given in Sections 4 and 5, respectively.

\section{Methodology}

\subsection{Research Procedure}

The process of developing the proposed methodology (Figure 2) begins by establishing an indicator system based on the pressure-state-response (PSR) framework. Then, in order to avoid the inconvenience caused by the difference in the value range and units of the indicators, the monitoring values of each indicator are normalized. In subsequent steps, the smoothing technique of the FDA method is used to convert the discrete values of each indicator into a continuous function curve. A dynamic matter-element extension (D-MEE) model is established by replacing the discrete values in the traditional matter-element extension model with the generated continuous function curve. In this evaluation model, in order to consider the correlation among the indicators, the indicator weights are determined by the D-CRITIC method, which is established by combining the FDA method and CRITIC method. Furthermore, in order to consider the influence of the seepage safety status of different dam blocks on the overall seepage safety of the dam, the evaluation eigenvalues of each dam block are introduced into the construction of the spatial weight matrix, and the comprehensive score of the dam's overall seepage safety assessment is calculated. Eventually, the overall seepage safety level of the dam can be judged based on the comprehensive score and related grading standards.

\subsection{Indicator System Based on the PSR Framework}

To combine multiple sources of impacts and make the indicator system more comprehensive, the indicator system is established based on the pressure-state-response (PSR) framework [64]. Pressure indicators represent external environmental factors that may affect the seepage safety state. From the perspective of the formation mechanism of dam seepage, temperature, and water level difference (the difference between the upstream water level and the downstream water level) there are two environmental factors that mainly affect the change of seepage behavior. Therefore, temperature (C1) and water level difference (C2) are selected as pressure indicators. State indicators characterize the situation of the seepage safety at a specific time and are the main criteria for the safety assessment. In researches on the seepage problems of concrete gravity dams [8-16], the seepage behavior is usually reflected by seepage flow and dam foundation uplift pressure. Therefore, seepage flow (C3) and uplift pressure (C4) are regarded as state indicators. Response indicators inform on the response to the seepage safety state and can provide decision information on whether the monitoring data of state indicators are in the safe range. In the monitoring and assessment of dam seepage safety, judging the seepage safety level only according to the magnitude of seepage flow or uplift pressure is not reasonable, it is also necessary to analyze whether their trends are in the normal range. Therefore, response indicators in this paper include the rate of change in seepage flow (C5) and the rate of change in uplift pressure (C6). 
In a word, the indicator system based on the PSR framework can deal with the complex relationship among multisource indicators and objectively reflect the seepage safety state of concrete gravity dam.

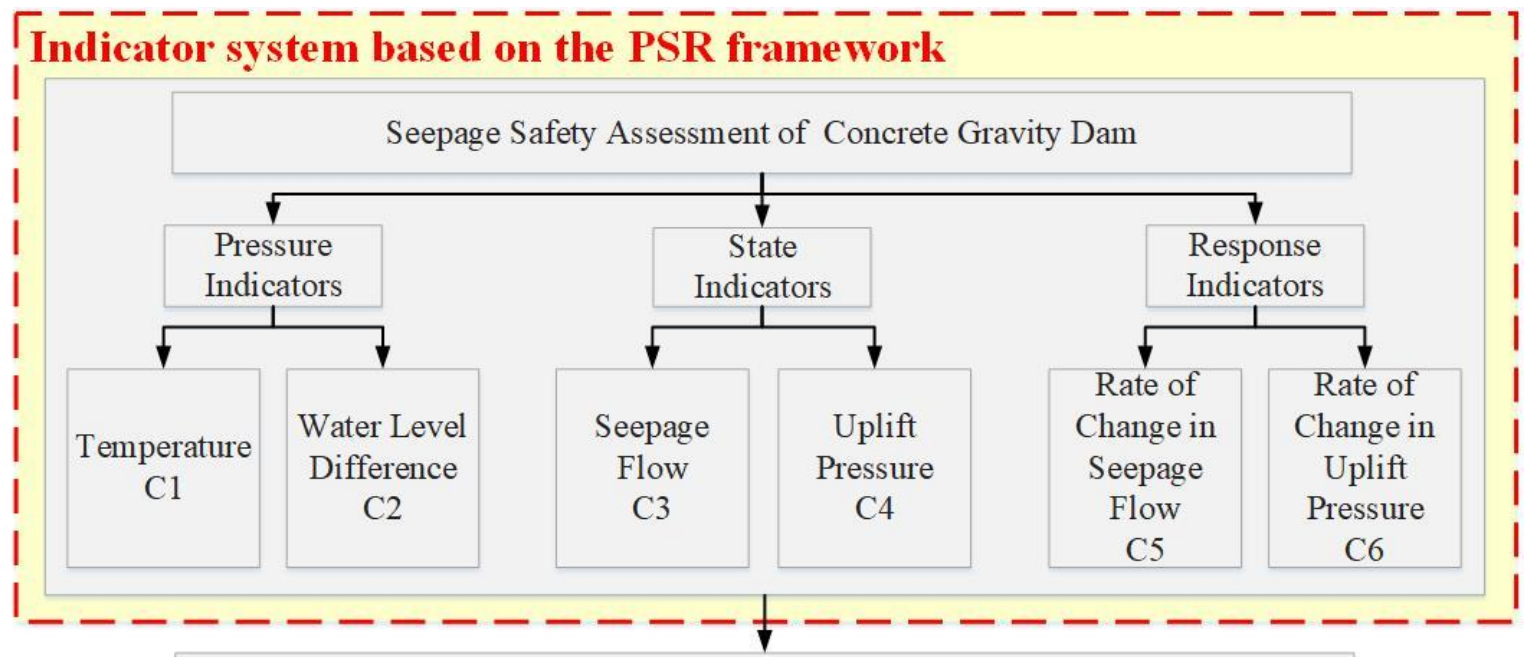

Normalize the monitoring values of the indicators

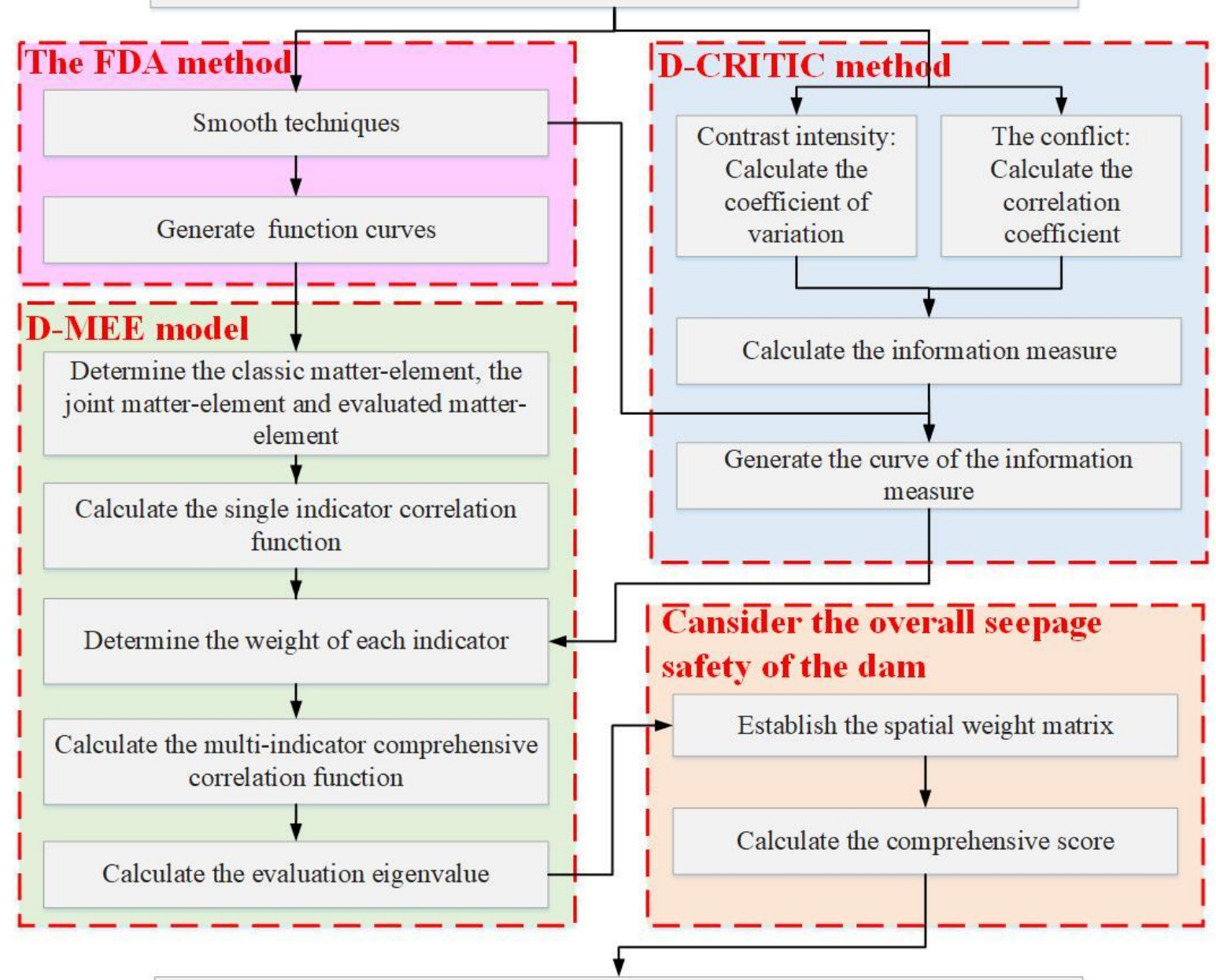

Assess the overall seepage safety level of the dam

Figure 2. Flowchart of the proposed methodology. 


\subsection{D-MEE Model for Seepage Safety Assessment}

\subsubsection{Functional Data Analysis (FDA)}

The main idea of FDA is to represent the discrete monitoring data from a time series as a continuous curve. The first step in FDA is to convert discrete monitoring values into continuous curves using interpolation or smoothing techniques [65]. If the sampling is well controlled and the monitoring error is considered negligible, interpolation is a good choice to generate the continuous curves, which pass through each observation data [41]. However, in most cases, monitoring errors are considered inevitable. Therefore, smoothing is the most common method to convert discrete monitoring values into continuous curves. The continuous curve generated by the smoothing method does not pass through each observation data; moreover, it is regarded as a curve with good smoothness that minimizes the squared distance to the observation data [42]. The main idea of smoothing techniques is to represent the function curve with a linear combination of basis functions $[65,66]$ :

$$
v_{i}(t)=\sum_{m=1}^{M} \varepsilon_{i m} \phi_{m}(t) i=1,2, \cdots, n ; t \in T
$$

where $M$ and $n$ are the numbers of basis functions and indicators, respectively; $T$ is the research time domain; $\phi_{m}(t)$ are the basis functions; and $\varepsilon_{i m}$ are the coefficients.

There are various basis functions, such as the B-spline basis function, Fourier basis function, and wavelet basis function. Fourier basis is optimal for periodic data, wavelet basis is more suitable for the data with frequent and severe fluctuations, and B-spline basis is the best choice for smoothing nonperiodic data [65]. The coefficients $\varepsilon_{i m}$ are determined by minimizing the squared distance method:

$$
\min \left\{\sum_{k=1}^{K}\left(\sum_{m=1}^{M} \varepsilon_{i m} \phi_{m}(t)-v_{i}\left(t_{i k}\right)\right)^{2}\right\}
$$

where $K$ is the observation number of the $i$-th indicator and $v_{i}\left(t_{i k}\right)$ is the normalized value of the $i$-th indicator at monitoring time point $t_{i k}$.

To eliminate the influence of different dimensions and units, the monitoring values of each indicator need to be normalized. According to the contribution of indicator change to seepage safety, all evaluation indicators are divided into two kinds, namely positive and reverse indicators [67]. The positive indicator indicates that the increase in indicator value is beneficial to seepage safety, that is, a larger indicator value is safer. The reverse indicator indicates that the increase in indicator value is harmful to seepage safety, that is, a smaller indicator value is safer. The following two equations [32] are adopted to normalize the positive indicator and the reverse indicator, respectively.

For the positive indicator,

$$
v_{i}\left(t_{i k}\right)=\frac{x_{i}^{\max }-x_{i}\left(t_{i k}\right)}{x_{i}^{\max }-x_{i}^{\min }}
$$

For the reverse indicator,

$$
v_{i}\left(t_{i k}\right)=\frac{x_{i}\left(t_{i k}\right)-x_{i}^{\min }}{x_{i}^{\max }-x_{i}^{\min }}
$$

where $x_{i}\left(t_{i k}\right)$ is the monitoring value of the $i$-th indicator at monitoring time point $t_{i k}$ and $x_{i}{ }^{\max }$ and $x_{i}{ }^{\mathrm{min}}$ are the maximum and minimum values of the monitoring value of the $i$-th indicator, respectively.

\subsubsection{D-MEE Model}

The matter-element extension (MEE) model was firstly proposed by Cai [23]. It can solve the contradictory and incompatibility problem from both qualitative and quantitative aspects [33]. A matter-element is the basic unit of the MEE model [24], the matter-element $R$ is an ordered triplet $R=[N, C, V]$, which contains three fundamental elements: matter-element name $(N)$, matter-element 
characteristics $(C)$, and values of matter-element characteristics $(V)$. For example, in this paper, the seepage safety assessment is the matter-element name $(N)$, the evaluation indicators are regarded as the matter-element characteristics $(C)$, and the values of matter-element characteristics $(V)$ are represented by the values corresponding to the indicators. The matter-element analysis first needs to determine the classical matter-element, the joint matter-element, and evaluated matter-element according to the evaluation indicators and the classification standard of safety level. Then, the safety level to which the evaluation object belongs can be judged by calculating the single indicator correlation function, the multi-indicators comprehensive correlation function, and the evaluation eigenvalue. The detailed steps can be found in the researches of Ma and Li [24,33].

The D-MEE model is similar to the MEE model. However, in contrast to the MEE model, the discrete data of the indicators are replaced by a smooth function fitted by the FDA in the D-MEE model and the evaluation result is a continuous function curve rather than a discrete value. The establishment process of the D-MEE model is described as follows.

Step 1: Determine the classic matter-element, the joint matter-element, and the evaluated-matter element.

The classic matter-element $R_{0 j}=\left[N_{0 j}, C_{i}, V_{0 i j}\right]$ is defined as follows.

$$
R_{0 j}=\left[\begin{array}{ccc}
N_{0 j} & C_{1} & V_{01 j} \\
& C_{2} & V_{02 j} \\
& \vdots & \vdots \\
& C_{n} & V_{0 n j}
\end{array}\right]=\left[\begin{array}{ccc}
N_{0 j} & C_{1} & \left\langle a_{01 j}, b_{01 j}\right\rangle \\
& C_{2} & \left\langle a_{02 j}, b_{02 j}\right\rangle \\
\vdots & \vdots \\
& C_{n} & \left\langle a_{0 n j}, b_{0 n j}\right\rangle
\end{array}\right]
$$

where $N_{0 j}$ is the $j$-th safety level, $j=1,2, \ldots, m ; C_{i}$ is the $i$-th indicator, $i=1,2, \ldots, n ; V_{0 i j}$ is the value range of the $i$-th indicator under the $j$-th safety level - that is, the classical domain; and $a_{0 i j}$ and $b_{0 i j}$ are the lower and upper limits of the classical domain, respectively. The calculation process of the classical matter-element can be referred to the researches of Mei, Ma and Li $[19,24,33]$.

Similarly, the joint matter-element $R_{p}=\left[N_{p}, C_{i}, V_{p i}\right]$ can be expressed as

$$
R_{p}=\left[\begin{array}{ccc}
N_{p} & C_{1} & V_{p 1} \\
& C_{2} & V_{p 2} \\
& \vdots & \vdots \\
& C_{n} & V_{p n}
\end{array}\right]=\left[\begin{array}{ccc}
N_{p} & C_{1} & \left\langle a_{p 1}, b_{p 1}\right\rangle \\
& C_{2} & \left\langle a_{p 2}, b_{p 2}\right\rangle \\
& \vdots & \vdots \\
& C_{n} & \left\langle a_{p n}, b_{p n}\right\rangle
\end{array}\right]
$$

where $N_{p}$ represents the whole body of the safety levels; $V_{p i}$ represents the value range of the indicator $C_{i}$-that is, the joint domain; and $a_{p i}$ and $b_{p i}$ are the upper and lower limits of the joint domain, respectively.

Then, evaluated matter-element $R_{t}$ is described as

$$
R_{t}=\left[\begin{array}{ccc}
N_{t} & C_{1} & v_{1}(t) \\
& C_{2} & v_{2}(t) \\
& \vdots & \vdots \\
& C_{n} & v_{n}(t)
\end{array}\right]
$$

where $N_{t}$ is the object to be evaluated, here is the dam seepage safety; $v_{i}(t)$ represents the function value of the indicator $C_{i}$.

Step 2: Calculate the single indicator correlation function.

To determine the degree of association of the $i$-th indicator with the $j$-th safety level, the correlation function is defined as follows.

$$
K_{j}\left(v_{i}(t)\right)=\frac{\rho\left(v_{i}(t), V_{0 i j}\right)}{D\left(v_{i}(t), V_{0 i j}, V_{p i}\right)}
$$


where,

$$
\begin{gathered}
D\left(v_{i}(t), V_{0 i j}, V_{p i}\right)=\left\{\begin{array}{r}
\rho\left(v_{i}(t), V_{p i}\right)-\rho\left(v_{i}(t), V_{0 i j}\right), v_{i}(t) \notin V_{0 i j} \\
-\left|a_{0 i j}-b_{0 i j}\right|, v_{i}(t) \in V_{0 i j}
\end{array}\right. \\
\rho\left(v_{i}(t), V_{0 i j}\right)=\left|v_{i}(t)-\frac{a_{0 i j}+b_{0 i j}}{2}\right|-\frac{b_{0 i j}-a_{0 i j}}{2} \\
\rho\left(v_{i}(t), V_{p i}\right)=\left|v_{i}(t)-\frac{a_{p i}+b_{p i}}{2}\right|-\frac{b_{p i}-a_{p i}}{2}
\end{gathered}
$$

Equation (10) represents the distance between $v_{i}(t)$ and its classical domain $V_{0 i j}$, while Equation (11) represents the distance between $v_{i}(t)$ and its joint domain $V_{p i}$ [32].

Step 3: Calculate the multi-indicator comprehensive correlation function.

$$
K_{j}(t)=\sum_{i=1}^{n} \alpha_{i}(t) K_{j}\left(v_{i}(t)\right)
$$

where $\alpha_{i}(t)$ is the weight of the $i$-th evaluation indicator, and it is determined by the D-CRITIC method in Section 2.4.

Step 4: Calculate the evaluation eigenvalue.

$$
E(t)=\frac{\sum_{j=1}^{m} j K_{j}(t)}{\sum_{j=1}^{m} K_{j}(t)}
$$

According to the $E(t)$ value, it is possible to determine the level to which the evaluation object belongs. A low value for $E(t)$ indicates a safer level and vice versa.

\subsection{D-CRITIC Method for Determining the Indicator Weights}

CRITIC is a method for determining the objective weights of the indicators [46]. The weights derived by the CRITIC method incorporate the contrast intensity of each indicator and the conflict among the indicators [53]. The contrast intensity can be measured by the standard deviation or coefficient of variation. The larger the standard deviation or coefficient of variation, the more information reflected by the data sample of the indicator. The conflict is considered by the correlation coefficient between the indicators. If the positive correlation between the two indicators is strong, the conflict between the two is low, indicating that the information reflected by the two indicators is similar [53]. The standard deviation can only reflect the absolute change in the indicator, while the coefficient of variation can reflect the relative change. Therefore, the coefficient of variation is selected to calculate the contrast intensity, and the Pearson correlation coefficient is used to calculate the conflict in this study. The following steps can implement the D-CRITIC method.

Step 1: Calculate the coefficient of variation $f_{i}\left(t_{i k}\right)$ of each indicator vector as follows

$$
f_{i}\left(t_{i k}\right)=\frac{\sigma_{i}\left(t_{i k}\right)}{\bar{v}_{i}}
$$

where $\sigma_{i}\left(t_{i k}\right)$ is the standard deviation of the $i$-th indicator at monitoring time point $t_{i k}, \bar{v}_{i}$ represents the average of the normalized value of the $i$-th indicator, and they can be calculated as follows

$$
\begin{gathered}
\bar{v}_{i}=\frac{1}{K} \sum_{k=1}^{K} v_{i}\left(t_{i k}\right) \\
\sigma_{i}\left(t_{i k}\right)=\sqrt{\frac{1}{K}\left[v_{i}\left(t_{i k}\right)-\bar{v}_{i}\right]^{2}}
\end{gathered}
$$


where $K$ is the observation number of the $i$-th indicator.

Step 2: Construct the symmetric matrix, with dimensions $n \times n$. The generic element $r_{i i^{\prime}}$ of the matrix is the Pearson correlation coefficient between the indicator vectors $v_{i}$ and $v_{i^{\prime}}$.

Step 3: Generate the curve of the information measure $I_{i}(t)$ as follows

$$
I_{i}\left(t_{i k}\right)=f_{i}\left(t_{i k}\right) \sum_{i=1}^{n}\left(1-\left|r_{i i^{\prime}}\right|\right)
$$

where $I_{i}\left(t_{i k}\right)$ is the information measure of the $i$-th indicator at monitoring time point $t_{i k}, i=1,2, \ldots, n$.

In the D-CRITIC method, in order to dynamically assign weights to the indicators, it is necessary to convert the discrete values of the information measure into continuous function curve. The curve of the information measure $I_{i}(t)$ can be generated based on the smoothing techniques of FDA:

$$
I_{i}(t)=\sum_{m=1}^{M^{*}} \varepsilon_{i m}^{*} \varphi_{m}(t) i=1,2, \cdots, n ; t \in T
$$

where $M^{*}$ and $n$ are the numbers of basis function and indicators, respectively; $T$ is the research time domain; $\varphi_{m}(t)$ are the basis functions; and $\varepsilon_{i m}{ }^{*}$ are the coefficients determined by minimizing the squared distance method.

$$
\min \left\{\sum_{k=1}^{K}\left(\sum_{m=1}^{M^{*}} \varepsilon_{i m}^{*} \varphi_{m}(t)-I_{i}\left(t_{i k}\right)\right)^{2}\right\}
$$

where $K$ is the observation number of the $i$-th indicator.

Step 4: Determine the dynamic weight of each indicator as follows

$$
\alpha_{i}(t)=\frac{I_{i}(t)}{\sum_{i=1}^{n} I_{i}(t)} i=1,2, \cdots, n
$$

\subsection{Calculation of the Comprehensive Score by Constructing the Spatial Weight Matrix}

The concrete gravity dam is composed of multiple dam blocks. In order to consider the influence of the seepage safety state of different dam blocks on the overall seepage safety of the dam, this paper introduces the evaluation eigenvalue of each dam block into the construction of the spatial weight matrix to calculate the comprehensive score of seepage safety assessment.

Suppose $L$ is the number of dam blocks. The comprehensive score can be calculated as follows.

Step 1: Establish the asymmetric spatial weight matrix $W$, with dimensions $L \times L$. The diagonal elements are set to zero, and the off diagonal element $W_{l l^{\prime}}(t)$ is specified as follows

$$
W_{l l^{\prime}}(t)=\frac{E_{l}(t)}{E_{l^{\prime}}(t)} d_{l l^{\prime}}
$$

where $E_{l}(t)$ and $E_{l^{\prime}}(t)$ are the evaluation eigenvalues of the $l$-th and the $l^{\prime}$-th dam block, respectively. $d_{l l^{\prime}}$ is the corresponding element in the adjacency-based spatial weight matrix, which is defined as follows

$$
d_{l l^{\prime}}= \begin{cases}1 & \left(\text { dam block } l \text { and dam block } l^{\prime} \text { are adjacent }\right) \\ 0 & \left(\text { dam block } l \text { and dam block } l^{\prime} \text { are not adjacent or } l=l^{\prime}\right)\end{cases}
$$

Step 2: Calculate the sum $\widetilde{W}(t)$ of the elements of each row in the matrix $W$. 
Step 3: Calculate the spatial weight $w_{l}(t)$ as follows:

$$
w_{l}(t)=\frac{\widetilde{W}_{l}(t)}{\sum_{l=1}^{L} \widetilde{W}_{l}(t)}
$$

Finally, the comprehensive score for seepage safety of the dam can be calculated as follows

$$
E^{\prime}(t)=\sum_{l=1}^{L} w_{l}(t) E_{l}(t)
$$

The seepage safety level can be determined according to the comprehensive score $E^{\prime}(t)$. A low value for $E^{\prime}(t)$ indicates a safer level and vice versa.

\section{Case Study}

\subsection{Project Overview}

The dynamic comprehensive assessment method was applied to a case study to assess the seepage safety for concrete gravity dam X located on the lower reaches of the Jinsha River in southwest China. The project started in 2006 and was completed in 2015. On 10 October 2012 the concrete gravity dam X officially lowered its sluice to store water, which marked that the first unit of hydropower station was about to go into operation and generate electricity. Concrete gravity dam X is mainly composed of nonspillway dam blockson both sides of the river, plants behind the left bank dam, a ship lift on the left bank, a spillway dam blockin the river, and an underground plant on the right bank. The dam crest elevation is $384 \mathrm{~m}$ and the total dam crest length is $909.26 \mathrm{~m}$. The normal water level is $380 \mathrm{~m}$ and the dead water level is $370 \mathrm{~m}$. Concrete gravity dam $X$ is mainly based on power generation, and has comprehensive benefits such as improved navigation conditions, flood control, irrigation, and sand interception. More information about the concrete gravity dam X can be obtained from the research of Zhong [68].

In this paper, the seepage monitoring data of October 2012 were selected to conduct the seepage safety assessment. The uplift pressure was measured by the pore pressure meters distributed on the dam foundation. The pore pressure meters were arranged on the transverse drainage gallery, and there were generally no less than three pore pressure meters on each monitoring section. The seepage flow was measured by the triangular weirs, which were arranged in the drainage gallery and at the outlet of the drainage hole. The upstream water level and the downstream water level were observed synchronously by the water level gauges, which were arranged at the dam block with a stable water level in the upstream and the dam toe in the downstream, respectively. The temperature monitoring data were obtained from the meteorological monitoring stations in the dam area. As the dam was in the first impoundment period in October 2012, the upstream water level and the downstream water level were measured four times a day (the mean value of daily temperature measurements are used in this study), while the uplift pressure, seepage flow, and temperature data were read only once a day.

In order to consider the influence of the different dam blocks on the overall seepage safety status, the concrete gravity dam $X$ is roughly divided into four parts according to the blocks' different roles played in the dam operation: the left nonspillway (LN) dam block for retaining water on the left bank, the right nonspillway $(\mathrm{RN})$ dam block for retaining water on the right bank, the powerhouse $(\mathrm{PH})$ dam block for power generation, and the spillway (SW) dam block for flood discharge in the middle of the riverbed. The regional map of concrete gravity dam $X$ and the 3D dam model are shown in Figure 3 . According to the geological exploration data, the left bank foundation of concrete gravity dam $X$ is squeezed with compressive zone [8], the low strength and high permeability of rock mass poses a threat to seepage safety. In addition, the rock mass in the compressional zone has a small inclination, 
which is easy to form a slip control surface and is very unfavorable to the anti-sliding stability of the dam. Therefore, the LN dam block was chosen for implementing the method in detail.

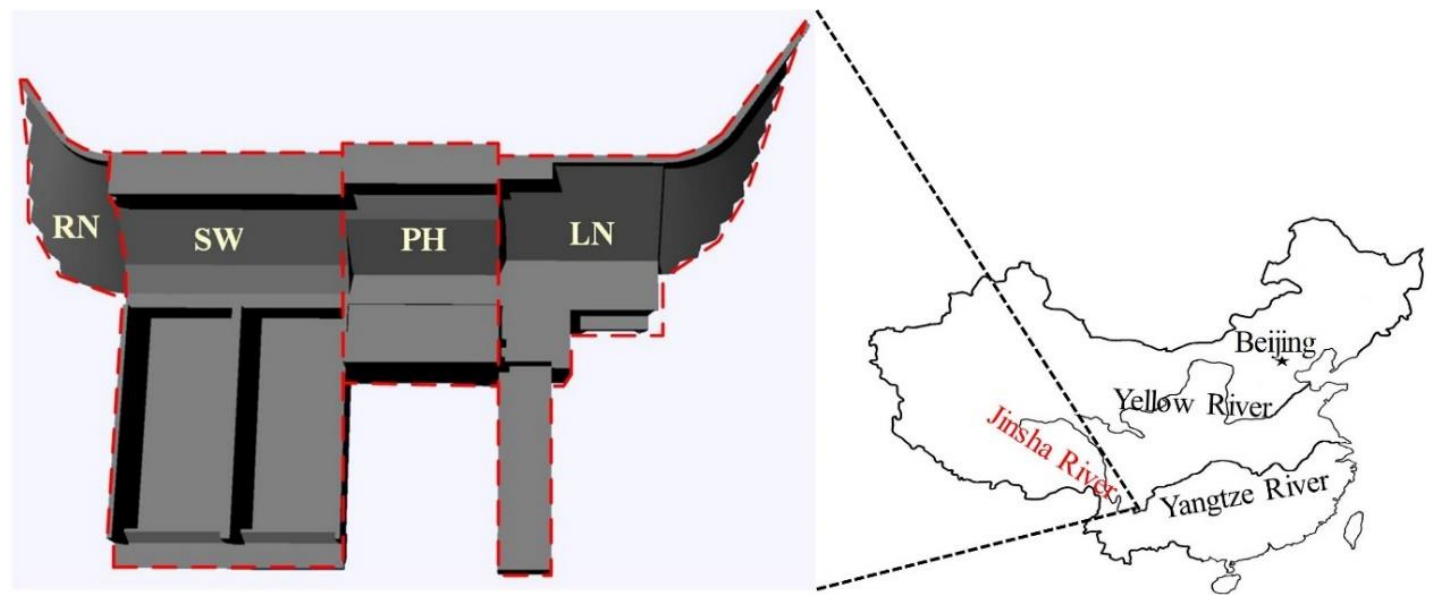

Figure 3. Regional map of concrete gravity dam $\mathrm{X}$ and the 3D dam model.

\subsection{Determining the Evaluation Indicators and Criteria}

As mentioned earlier, temperature (C1) and water level difference (C2) are proposed as pressure indicators, seepage flow (C3) and uplift pressure (C4) are proposed as state indicators, and the rate of change in seepage flow (C5) and the rate of change in uplift pressure (C6) are proposed as response indicators.

According to related research $[19,69]$, the seepage safety level can be divided into five classifications (I, II, III, IV, and V), which corresponds to the criterion set (Normal, Normal Basically, Little Abnormal, Abnormal, Dangerous). The classification standard for seepage safety level is shown in Table 1.

Table 1. Classification standard for seepage safety level.

\begin{tabular}{cccccccc}
\hline Classification & $\begin{array}{c}\text { Comprehensive } \\
\text { Score }\end{array}$ & C1 & C2 & C3 & C4 & C5 & C6 \\
\hline $\begin{array}{c}\text { I } \\
\text { (Normal) } \\
\text { II }\end{array}$ & $1-1.5$ & $0-0.2$ & $0-0.2$ & $0-0.2$ & $0-0.2$ & $0-0.2$ & $0-0.2$ \\
$\begin{array}{c}\text { (Normal Basically) } \\
\text { III }\end{array}$ & $1.5-2.5$ & $0.2-0.4$ & $0.2-0.4$ & $0.2-0.4$ & $0.2-0.4$ & $0.2-0.4$ & $0.2-0.4$ \\
$\begin{array}{c}\text { (Little Abnormal) } \\
\text { IV } \\
(\text { Abnormal) } \\
\text { V } \\
\text { (Dangerous) }\end{array}$ & $2.5-3.5$ & $0.4-0.6$ & $0.4-0.6$ & $0.4-0.6$ & $0.4-0.6$ & $0.4-0.6$ & $0.4-0.6$ \\
\hline
\end{tabular}

As the value domains and units of the measured values of evaluation indicators are different, it is necessary to normalize the measuring values of each indicator. The measuring values should be normalized according to Formula (4), because larger measuring values are worse for the status of seepage safety. Then, the grade boundary value of each indicator can be obtained [19].

Because a low value for $E^{\prime}(t)$ (comprehensive score) indicates safer state of the dam seepage and vice versa. Here, in reference to similar studies that used the MEE model [44], this study defines the seepage safety level as I when $1<E^{\prime}(t)<1.5$ and as $\mathrm{V}$ when $4.5<E^{\prime}(t)<5$. The seepage safety levels are II, III, and IV when $i-0.5<E^{\prime}(t)<i+0.5, i=2,3,4$, respectively. 


\subsection{Generate the Function Curve for Each Indicator Using FDA}

The monitoring values of the indicators in October 2012 are provided by the automated seepage safety monitoring system, the seepage flow data on 3 and 9 October of the LN dam block are missing. Because the evaluation indicators proposed in this study are the reverse indicators, the smaller the indicator value, the safer the evaluation result. Therefore, Formula (4) was used to normalize the monitoring data of the indicators. Then, the fourth order B-spline basis function is used to smooth the data of each indicator because the monitoring data selected in this paper is nonperiodic and inevitably have monitoring errors. At last, the discrete data are converted into a continuous function curve over the same time domain according to the Equations (1) and (2), although the monitoring values of seepage flow on the 3 and 9 October are missing, as shown in Figure 4. The rate of change in seepage flow and the rate of change in uplift pressure are obtained by the derivative analysis of the FDA method, as shown in Figure 4e,f.

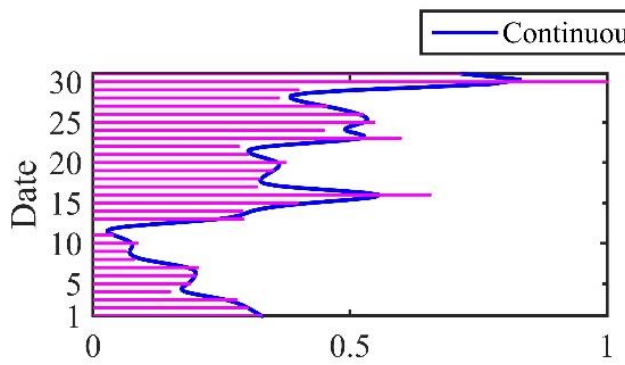

(a)

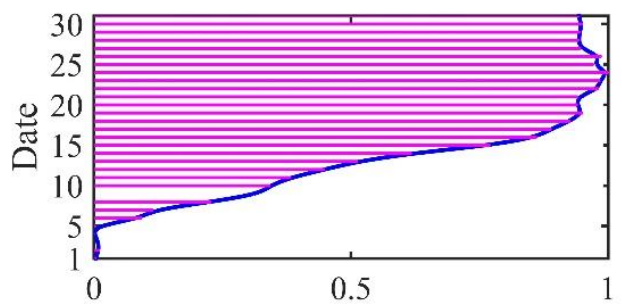

(c)

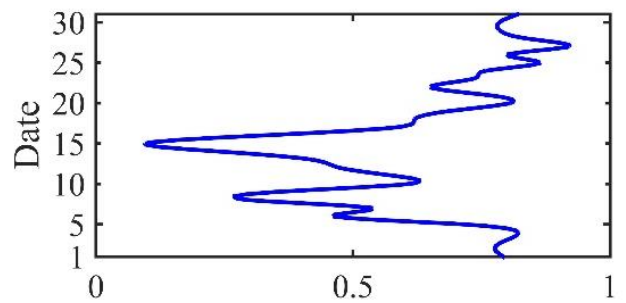

(e)

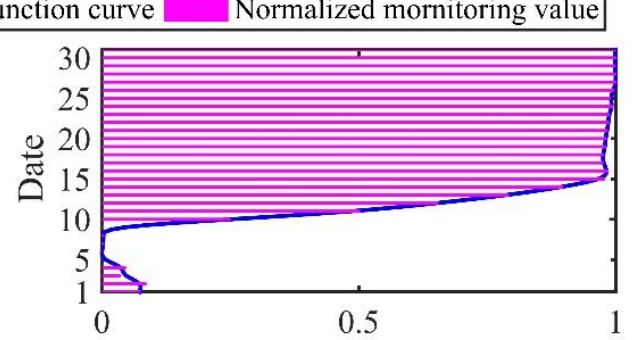

(b)

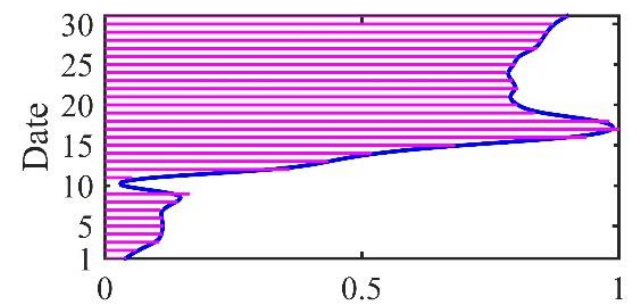

(d)

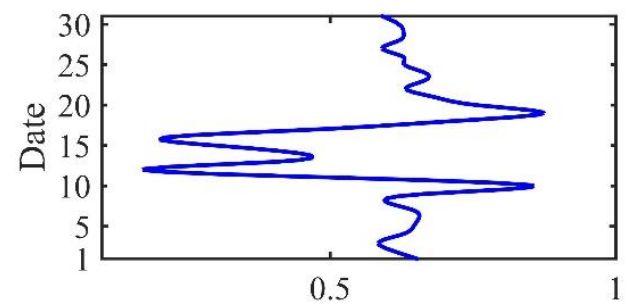

(f)

Figure 4. The curves of the indicators: (a) Temperature $\mathrm{C} 1$; (b) water level difference $\mathrm{C} 2$; (c) seepage flow C3; (d) uplift pressure C4; (e) rate of change in seepage flow C5; and (f) rate of change in uplift pressure C6. 
3.4. Determine the Classic Matter-Element, the Joint Matter-Element, and Evaluated Matter-Element

The classic matter-element $R_{0 j}=\left[N_{0 j}, C_{i}, V_{0 j}\right]$ is set as follows

$$
R_{0 j}=\left[\begin{array}{cccccc} 
& N_{01} & N_{02} & N_{03} & N_{04} & N_{05} \\
C_{1} & (0,0.2) & (0.2,0.4) & (0.4,0.6) & (0.6,0.8) & (0.8,1) \\
C_{2} & (0,0.2) & (0.2,0.4) & (0.4,0.6) & (0.6,0.8) & (0.8,1) \\
C_{3} & (0,0.2) & (0.2,0.4) & (0.4,0.6) & (0.6,0.8) & (0.8,1) \\
C_{4} & (0,0.2) & (0.2,0.4) & (0.4,0.6) & (0.6,0.8) & (0.8,1) \\
C_{5} & (0,0.2) & (0.2,0.4) & (0.4,0.6) & (0.6,0.8) & (0.8,1) \\
C_{6} & (0,0.2) & (0.2,0.4) & (0.4,0.6) & (0.6,0.8) & (0.8,1)
\end{array}\right]
$$

The joint matter-element $R_{p}=\left[N_{p}, C_{i}, V_{p}\right]$ is

$$
R_{p}=\left[\begin{array}{lll}
N_{p} & C_{1} & (0,1) \\
& C_{2} & (0,1) \\
& C_{3} & (0,1) \\
& C_{4} & (0,1) \\
& C_{5} & (0,1) \\
& C_{6} & (0,1)
\end{array}\right]
$$

Evaluated matter-element $R_{t}$ is described as

$$
R_{t}=\left[\begin{array}{ccc}
N_{t} & C_{1} & v_{1}(t) \\
& C_{2} & v_{2}(t) \\
& C_{3} & v_{3}(t) \\
& C_{4} & v_{4}(t) \\
& C_{5} & v_{5}(t) \\
& C_{6} & v_{6}(t)
\end{array}\right]
$$

where $N_{t}$ represents the dam seepage safety and $v_{i}(t)$ represents the function curve of the indicator $C_{i}$, which is generated by FDA.

The single indicator correlation function $K_{j}\left(v_{i}(t)\right)$ can then be calculated according to Equations (8)-(11).

\subsection{Determine the Weights of the Indicators Based on the D-CRITIC Method}

The correlation among indicators is shown in Figure 5. The radius and color of the circle in the figure represent the magnitude of the Pearson correlation $\mathrm{R}$ between the parameters. The numbers on the circle represent the Pearson correlation coefficients. Generally speaking, $|R|=0$ is an uncorrelated relationship, $0<|R|<0.4$ is a weak correlation, $0.4<|R|<0.75$ is a correlation, $0.75<|R|<1$ is a strong correlation, and $|R|=1$ is a complete correlation. Obviously, there is a strong correlation among $\mathrm{C} 2, \mathrm{C} 3$, and $\mathrm{C} 4$. To consider the impact of the correlation among indicators, this study proposes the D-CRITIC method to determine the weights of the indicators. The detailed calculation process of the D-CRITIC method is described in Section 2.4. The dynamic weight curves of the indicators are shown in Figure 6. 


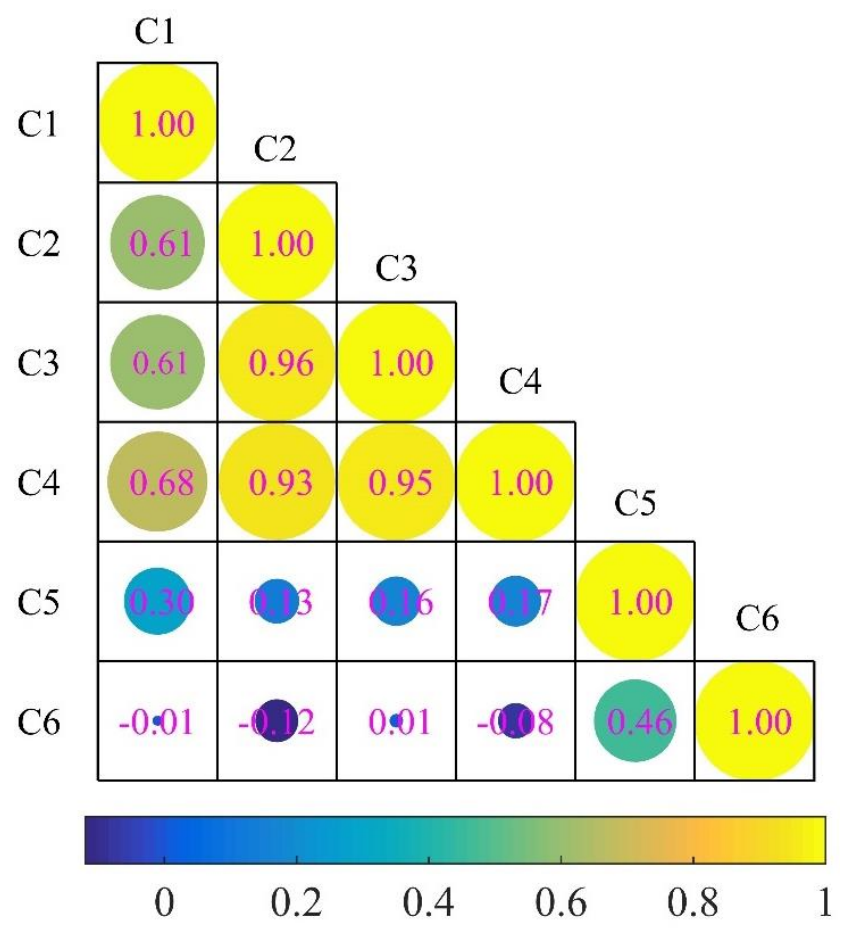

Figure 5. Pearson correlation analysis.

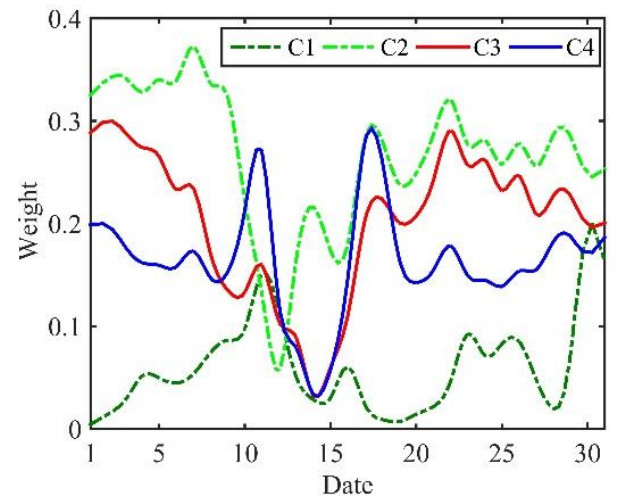

(a)

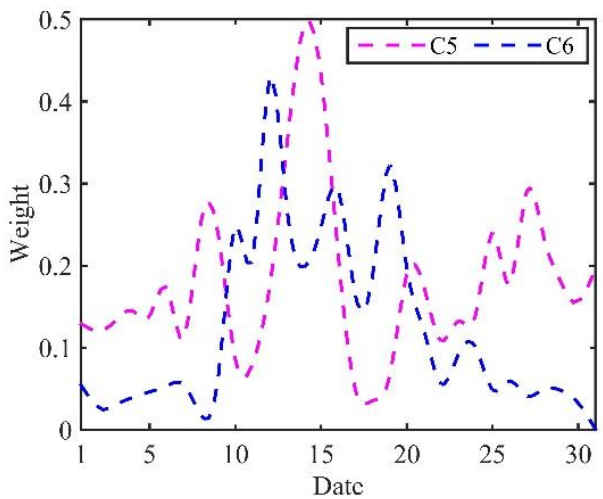

(b)

Figure 6. Dynamic weight curves of the indicators: (a) Weight curves of pressure indicators and state indicators and (b) weight curves of response indicators.

As shown in Figure 6a, the dynamic weight curves of pressure indicators and state indicators show a sharp decline and then rise sharply during the period from 9 to 17 October. Compared with Figure $6 \mathrm{a}$, the dynamic weight curves of response indicators in Figure $6 \mathrm{~b}$ show an opposite trend during the same period.

After obtaining the weights of the indicators $\alpha_{i}(t)$, the multi-indicator comprehensive correlation function $K_{j}(t)$ can be obtained from Equation (12).

\subsection{Calculate the Comprehensive Score}

According to Equation (12), the evaluation eigenvalue of LN dam block $E(t)$ can then be calculated. The remaining three dam blocks are evaluated in the same way, and the evaluation eigenvalue curves of the different dam blocks are shown in Figure 7. 


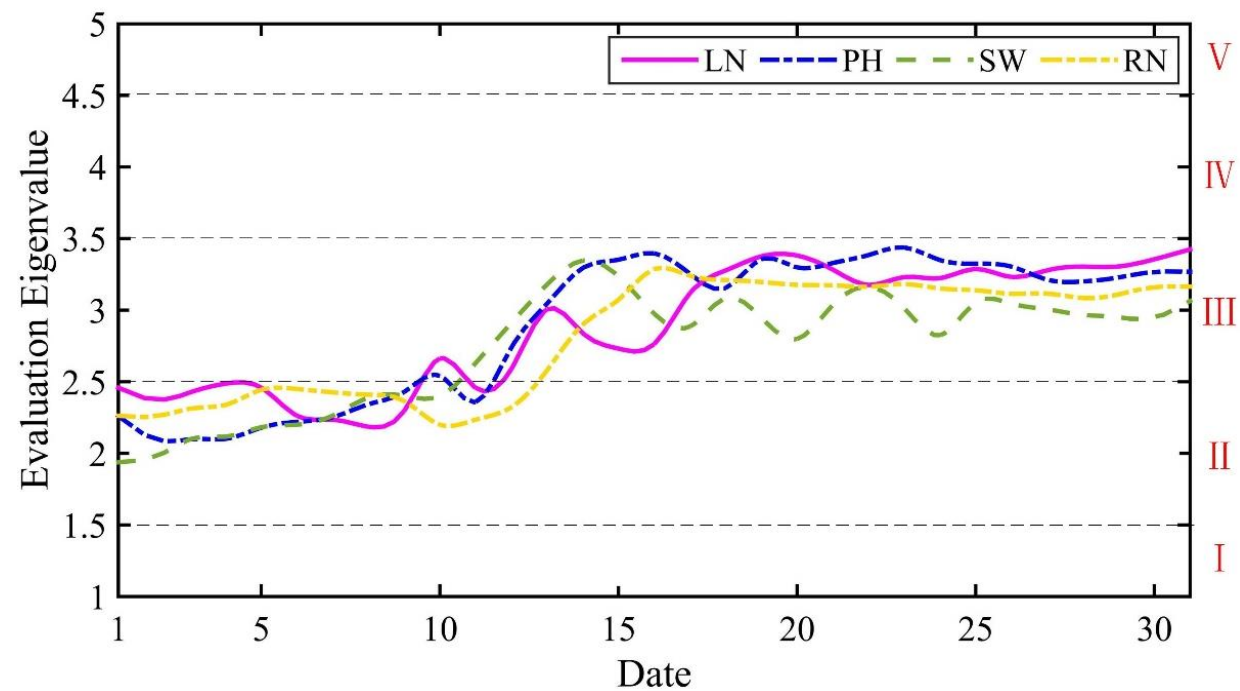

Figure 7. Evaluation eigenvalue curves of the dam blocks.

It can be seen that all evaluation eigenvalue curves dynamically change between level II (Normal Basically) and level III (Little Abnormal). However, the change trend of the eigenvalue curve for each dam block is different. Obviously, it is not appropriate to judge the overall seepage safety level by only one dam block. In addition, the evaluation eigenvalue curves of LN dam block and SW dam block fluctuate greatly. While the evaluation eigenvalue curve of $\mathrm{RN}$ dam block and $\mathrm{PH}$ dam block has little fluctuation, which may be related to their respective structural characteristics and foundation conditions. To consider the impact of different dam blocks on the overall seepage safety of the dam and calculate the comprehensive score, this study has established the spatial weight matrix. The calculation process is described in Section 2.5. The comprehensive score curve of the seepage safety is shown in Figure 8. The evaluation results also dynamically change between level II (Normal Basically) and level III (Little Abnormal). In addition, it can be clearly seen that the trend of the comprehensive score curve is similar to the evaluation eigenvalue curve of the PH dam block. This indicates that the PH dam block has the most important influence on the overall seepage safety of the dam. In fact, the seepage safety of the PH dam block is also of great concern because of its complex internal features and its important role in power generation.

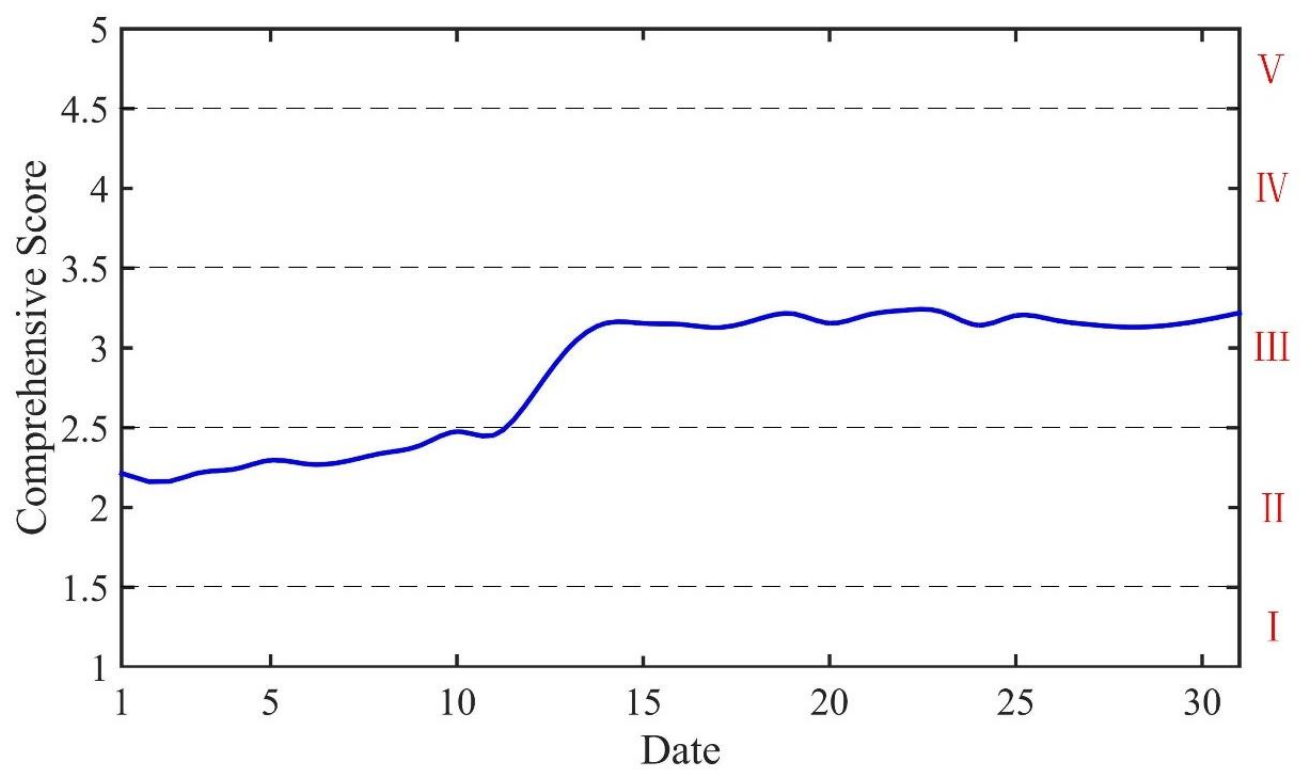

Figure 8. Comprehensive score curve. 


\section{Discussion}

First, to illustrate the effectiveness and superiority of the D-MEE method, it is compared with the set pair analysis method, fuzzy comprehensive evaluation method, and matter-element extension method. The data come from the monitoring data from 5 to 15 October. The comparison of results is shown in Table 2.

Table 2. Comparison results of the seepage safety level using various methods.

\begin{tabular}{ccccc}
\hline Data & $\begin{array}{c}\text { Set Pair Analysis } \\
\text { Method }\end{array}$ & $\begin{array}{c}\text { Fuzzy Comprehensive } \\
\text { Evaluation Method }\end{array}$ & $\begin{array}{c}\text { Matter-Element } \\
\text { Extension Method }\end{array}$ & D-MEE Method \\
\hline 5 & II & II & III & II \\
6 & II & II & II & II \\
7 & II & II & II & II \\
8 & II & II & II & II \\
9 & II & II & III & II \\
10 & II & II & II & II \\
11 & III & III & III & III \\
12 & III & II & III & III \\
13 & III & III & III & III \\
14 & IV & IV & III & III \\
15 & III & & & \\
\hline
\end{tabular}

The results of the D-MEE method are highly consistent with the results of the other methods. As seen in the results, the evaluation results on $6,7,8$, and 12 October are identical. In addition, the results of the D-MEE method are close to those of other methods. That is, $90 \%$ of results are the same as those from the matter-element extension method, and $70 \%$ of the results are the same as those of the fuzzy comprehensive evaluation method and the set pair analysis method.

The D-MEE method is most representative amongst all methods. According to the evaluation results of several methods, on 5, 6, 7, 8, and 11 October, most of the levels are II and on 10, 12, $13,14,15$ October, most of the levels are III. The same conclusion can be drawn by the D-MEE method individually.

The D-MEE method has the advantage of solving the problem of missing data. Because the seepage flow data of the LN dam block were missing on 9 October, the safety level on 9 October could not be obtained by other methods. However, the D-MEE method can effectively solve this problem by the continuous function curve generated by the smoothing technique.

Second, to illustrate the necessity of considering the correlation among indicators when determining the weights, the method proposed in this paper is compared with the case that ignores the correlation among indicators and determines the weights using the entropy method.

As shown in Figure 9, in the case of ignoring the correlation among indicators, the comprehensive score will be greater than that when considering the correlation among indicators. Because the indicator weight has a crucial impact on the evaluation results, this study calculates the average weight of each evaluation indicator of each dam block under these two conditions, as shown in Figure 10. It can be seen in Figure 10 that the weights of key indicators C2, C3, and C4 will increase significantly in the case of ignoring the correlation among indicators, which means that the conflict among C2, C3, and C4 is large, reflecting that their information similarity is small. However, according to the correlation analysis of Figure 5, the correlation coefficient among C2, C3, and C4 is greater than 0.9 , which is a strong correlation; that is, the information similarity reflected by C2, C3, and C4 is large. Therefore, it is necessary to consider the correlation among indicators in the calculation of indicator weights. 


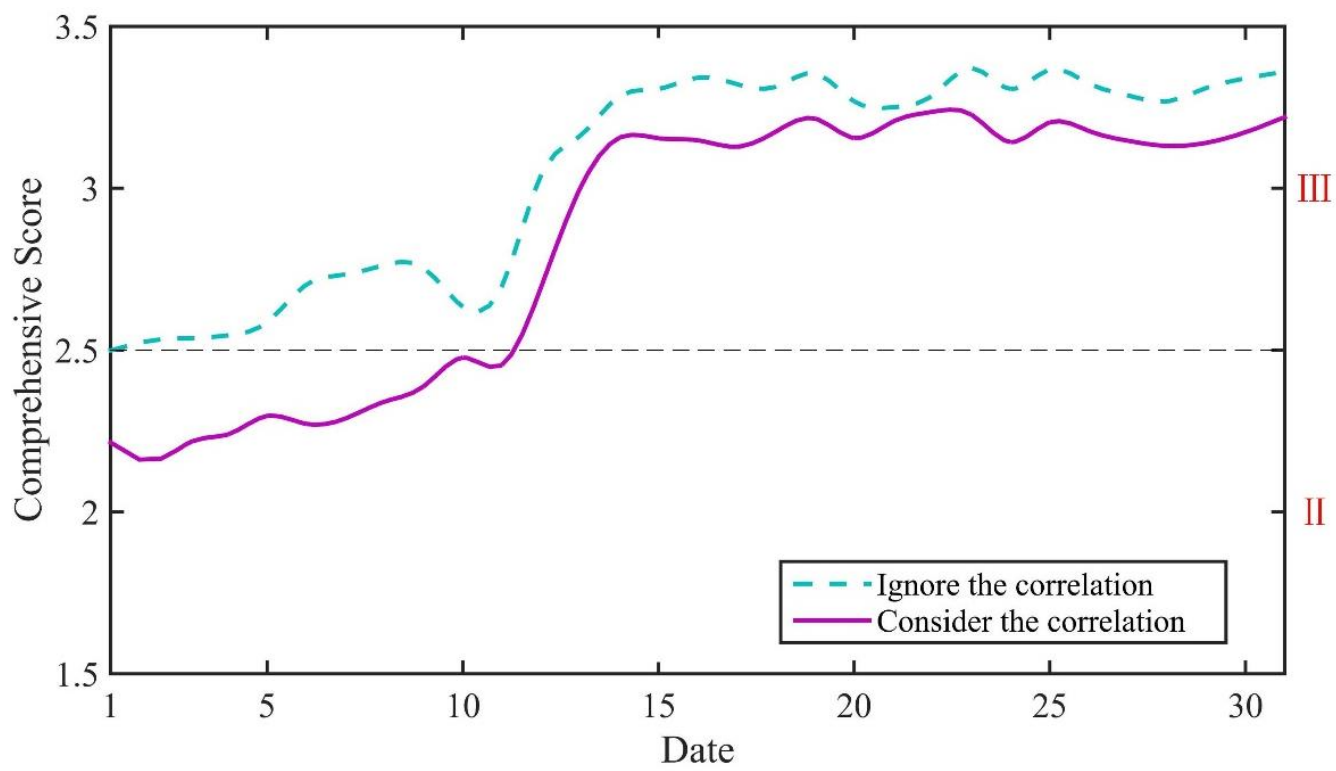

Figure 9. Discussion of the necessity of considering the correlation among indicators.

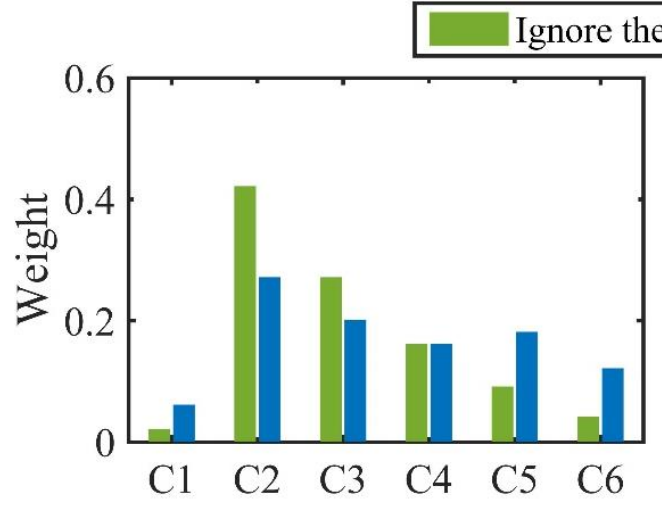

(a)

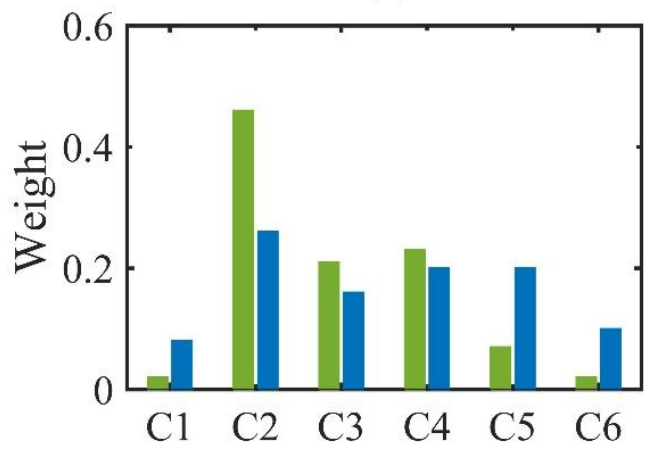

(c)

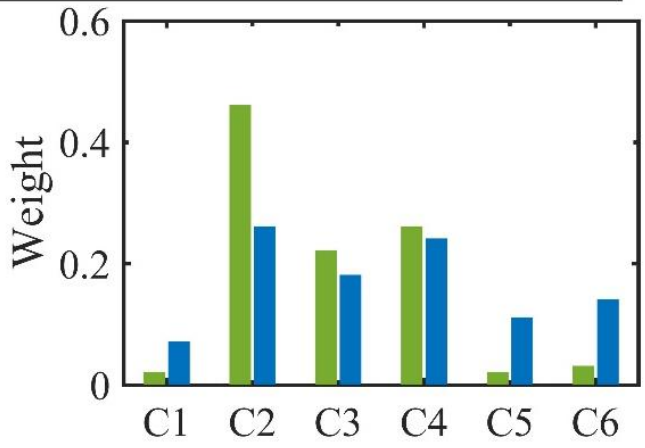

(b)

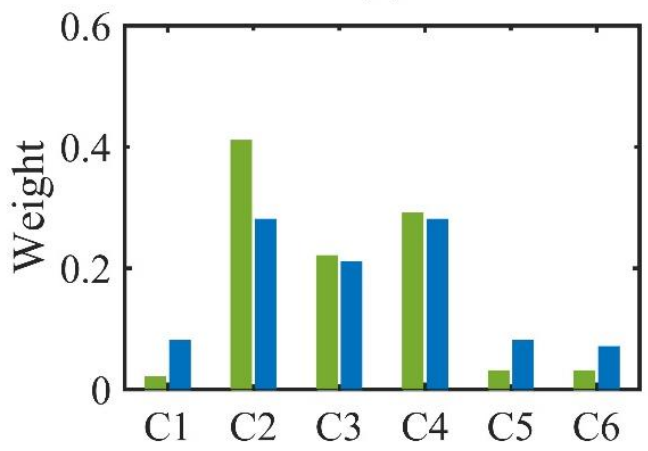

(d)

Figure 10. Average weight of each indicator for different dam blocks: (a) LN dam block; (b) PH dam block; (c) SW dam block; and (d) RN dam block.

In conclusion, compared with other commonly used methods for seepage safety evaluation, the D-MEE method proposed in this paper is effective and superior. At the same time, in order to obtain more reasonable and accurate evaluation results, it is necessary to consider the correlation among the indicators when determining the indicator weights. In addition, according to the analysis of Figures 7 and 8 in the previous chapter, the seepage safety state of each dam block is different, and the combination of the safety state of each dam block through the spatial weight matrix can reflect the 
overall seepage safety level of the dam. Therefore, the evaluation method proposed in this paper is of great significance for the dynamic comprehensive assessment of dam seepage safety and can be applied to other similar fields.

\section{Conclusions}

Seepage safety assessment is an important work to ensure dam safety. In this paper, based on the matter-element extension (MEE) model and functional data analysis (FDA), a dynamic matter-element extension (D-MEE) model is proposed to dynamically and comprehensively assess the seepage safety of a dam. It considers not only the correlation among indicators, but also considers the influence of different dam sections on the overall seepage safety. The proposed method was successfully applied to the seepage safety assessment of a concrete gravity dam in southwest China. As discussed in the paper, and illustrated by the real-life hydraulic engineering application example, three advantages of this method can be summarized:

- The proposed D-MEE model converts the discrete monitoring data into a dynamic and continuous function curve through smoothing technology, which can reflect the dynamic change process of seepage safety more intuitively and comprehensively. In addition, more information can be obtained by the derivative analysis of the function curves. D-MEE can also solve the problems of missing data and unequal sampling.

- $\quad$ The proposed D-CRITIC method effectively considers the correlation among indicators and avoids the overlap of indicator information. At the same time, it determines the weights according to the dynamic change of the indicators, making the weights more accurate.

- The spatial weight integrated with the dynamic evaluation eigenvalues can be effectively used to assess the overall seepage safety and make the evaluation results more reasonable.

Overall, the method proposed in this paper is suitable for dynamic comprehensive assessment of multi-indicator and multiregion problems. For future work, more indicators that affect the seepage safety, such as creep and hydration temperature, can be considered into the indicator system to establish a more comprehensive indicator system. In addition, the proposed method can be integrated into the seepage automatic monitoring system for more effective assessment of seepage safety.

Author Contributions: Conceptualization, X.W., H.Y. and P.L.; Methodology, H.Y. and P.L.; Formal Analysis, H.Y.; Investigation, P.L.; Data Curation, C.W.; Writing-Original Draft Preparation, H.Y.; Writing—Review and Editing, X.W., H.Y., J.Z. and J.Y.

Funding: This research was funded by the National Key R\&D Program of China under Grant No. 2018YFC0407101, the Science Fund for Creative Research Groups of the National Natural Science Foundation of China under Grant No. 51621092, and the National Natural Science Foundation of China under Grant No. 51439005.

Acknowledgments: The authors are grateful to the editor and the reviewers of this paper, whose comments and suggestions significantly improved the quality of the paper.

Conflicts of Interest: The authors declare no conflict of interest.

\section{References}

1. Zhao, H.; Guo, S.; Zhao, H. Comprehensive performance assessment on various battery energy storage systems. Energies 2018, 11, 2841. [CrossRef]

2. Scott, C.A.; Sugg, Z.P. Global energy development and climate-induced water scarcity-Physical limits, sectoral constraints, and policy imperatives. Energies 2015, 8, 8211-8225. [CrossRef]

3. General Office of the State Council. Available online: http://www.gov.cn/zhengce/content/2014-11/19/ content_9222.htm (accessed on 29 January 2019).

4. Nan, D.; Shigemitsu, T.; Zhao, S.D. Investigation and analysis of attack angle and rear flow condition of contra-rotating small hydro-turbine. Energies 2018, 11, 1806. [CrossRef]

5. Mridha, S.; Maity, D. Experimental investigation on nonlinear dynamic response of concrete gravity dam-reservoir system. Eng. Struct. 2014, 80, 289-297. [CrossRef] 
6. Karastathis, V.K.; Karmis, P.N.; Drakatos, G.; Stavrakakis, G. Geophysical methods contributing to the testing of concrete dams. Application at the Marathon Dam. J. Appl. Geophys. 2002, 50, 247-260. [CrossRef]

7. Ren, Q.; Xu, L.; Wan, Y. Research advance in safety analysis methods for high concrete dam. Sci. China Ser. E-Technol. Sci. 2007, 50, 62-78. [CrossRef]

8. Cheng, Z.; Wang, X.; Ren, B.; Lv, P.; Zhu, X. Simulation of complex seepage field of a gravity dam foundation using a CFD-based approach. J. Hydraul. Eng. 2018, 144. [CrossRef]

9. Bretas, E.M.; Lemos, J.V.; Lourenço, P.B. Hydromechanical analysis of masonry gravity dams and their foundations. Rock Mech. Rock Eng. 2013, 46, 327-339. [CrossRef]

10. Li, M.; Guo, X.; Shi, J.; Zhu, Z. Seepage and stress analysis of anti-seepage structures constructed with different concrete materials in an RCC gravity dam. Water Sci. Eng. 2015, 8, 326-334. [CrossRef]

11. Ministry of Water Resources of the People's Republic of China. SL 319-2005 Design Code for Concrete Gravity Dams; China Water Conservancy and Hydropower Press: Beijing China, 2005; pp. 12-13.

12. Ministry of Water Resources of the People's Republic of China. SL 601-2013 Technical Specification for Concrete Dam Safety Monitoring; China Water Resources and Hydropower Press: Beijing China, 2013; pp. 15-18.

13. Ministry of Water Resources of the People's Republic of China. SL 258-2017 Guidelines on Dam Safety Evaluation; China Water Resources and Hydropower Press: Beijing China, 2017; p. 34.

14. Zhu, X.; Wang, X.; Li, X.; Liu, M.; Cheng, Z. A new dam reliability analysis considering fluid structure interaction. Rock Mech. Rock Eng. 2018, 51, 2505-2516. [CrossRef]

15. Jiang, H.; Ma, F.; Wu, S. Comprehensive investigation of leakage problems for concrete gravity dams with penetrating cracks based on detection and monitoring data: A case study. Struct. Control Health Monit. 2017, $25, \mathrm{e} 2127$.

16. Zhu, K.; Gu, C.; Qiu, J.; Li, H. The analysis of the concrete gravity dam's foundation uplift pressure under the function of typhoon. Math. Probl. Eng. 2016, 2016, 2834192. [CrossRef]

17. He, Y.; Zhao, M.; Wang, K.; Liu, P. Fuzzy comprehensive evaluation of earth rockfill dam seepage security risk based on cloud model. Water Resour. Power 2018, 36, 83-86.

18. Su, H.; Sun, X. Comprehensive evaluation and tendency prediction model for concrete dam seepage behavior. Yangtze River 2013, 44, 95-99.

19. Mei, Y.; Zhong, Y. Fuzzy extension evaluation model of dam seepage behavior based on entropy weight. Water Resour. Power 2011, 29, 58-61.

20. Zadeh, L.A. Fuzzy sets. Inform. Control 1965, 8, 338-353. [CrossRef]

21. Zhao, K. Set pair and set pair analysis-a new concept and systematic analysis method. In Proceedings of the National Conference on System Theory and Regional Planning, Baotou, China, August 1989; pp. 87-91.

22. Garg, H.; Kumar, K. Distance measures for connection number sets based on set pair analysis and its applications to decision-making process. Appl. Intell. 2018, 48, 3346-3359. [CrossRef]

23. Cai, W. The extension set and incompatibility problem. J. Sci. Explor. 1983, 1, 81-93.

24. Ma, L.; Chen, H.; Yan, H.; Li, W.; Zhang, J.; Zhang, W. Post evaluation of distributed energy generation combining the attribute hierarchical model and matter-element extension theory. J. Clean. Prod. 2018, 184, 503-510. [CrossRef]

25. Tang, J.; Wang, C.; Lin, N.; Li, Z.; Li, H.; Mao, Z. Application of matter-element model in soil nutrient evaluation of ecological fragile region. Chin. Geogr. Sci. 2009, 19, 168-176. [CrossRef]

26. Li, K.; Hou, K. Dynamic extension evaluation of soil and water environmental quality in metal mine and its improvement measure. Res. J. Chem. Environ. 2012, 16, 97-101.

27. Wang, J.B. Classification and stability study on surrounding rock of Hipparion red clay in Shi-lou Tunnel. Master's Thesis, Northwest University, Xian, China, 2014.

28. Zhao, B.; Xu, W.; Liang, G.; Meng, Y. Stability evaluation model for high rock slope based on element extension theory. Bull. Eng. Geol. Environ. 2015, 74, 301-314. [CrossRef]

29. Liu, J.; Xu, J.; Bai, E.; Gao, Z. Durability evaluation analysis of reinforced concrete structures based on extension method. Adv. Mater. Res. 2011, 163-167, 3354-3358. [CrossRef]

30. Xie, D. The researching about evaluation methods that concrete resists sulfate erosion under the freeze thaw-dry wet cycle condition. Master's Thesis, Chongqing Jiaotong University, Chongqing, China, 2015.

31. Lian, H. Study and evaluation of concrete durability in the action of carbonization-sulfate attack-dry-wet cycle. Master's Thesis, North China University of Water Resources and Electric Power, Zhengzhou, China, 2017. 
32. Wang, X.; Wang, G.; Wu, Y.; Xu, Y.; Gao, H. Comprehensive assessment of regional water usage efficiency control based on game theory weight and a matter-element model. Water 2017, 9, 113. [CrossRef]

33. Li, J.; Wu, F.; Li, J.; Zhao, Y. Research on risk evaluation of transnational power networking projects based on the matter-element extension theory and granular computing. Energies 2017, 10, 1523. [CrossRef]

34. Liu, D.; Zhao, X. Method and application for dynamic comprehensive evaluation with subjective and objective information. PLoS ONE 2013, 8, e83323. [CrossRef] [PubMed]

35. Liu, J.; Guo, L.; Jiang, J.; Hao, L.; Liu, R.; Wang, P. Evaluation and selection of emergency treatment technology based on dynamic fuzzy grey method for chemical contingency spills. J. Hazard. Mater. 2015, 299, 306-315. [CrossRef] [PubMed]

36. Wang, T.; Xu, S. Dynamic successive assessment method of water environment carrying capacity and its application. Ecol. Indic. 2015, 52, 134-146. [CrossRef]

37. Wang, Q.; Zhang, L.; Hu, J.; Wang, H.; Li, K. A dynamic and non-linear risk evaluation methodology for high-pressure manifold in shale gas fracturing. J. Nat. Gas Sci. Eng. 2016, 29, 7-14. [CrossRef]

38. Wu, D.; Ning, S. Dynamic assessment of urban economy-environment-energy system using system dynamics model: A case study in Beijing. Environ. Res. 2018, 164, 70-84. [CrossRef]

39. Zarei, E.; Azadeh, A.; Khakzad, N.; Aliabadi, M.M.; Mohammadfam, I. Dynamic safety assessment of natural gas stations using Bayesian network. J. Hazard. Mater. 2017, 321, 830-840. [CrossRef] [PubMed]

40. Ramsay, J.O. When the data are functions. Psychometrika 1982, 47, 379-396. [CrossRef]

41. Yan, F.; Liu, L. Water quality assessment of the Li Canal using a functional fuzzy synthetic evaluation model. Environ. Sci. Proc. Imp. 2014, 16, 1764-1771.

42. Yan, F.; Liu, L.; Li, Y.; Zhang, Y.; Chen, M.; Xing, X. A dynamic water quality index model based on functional data analysis. Ecol. Indic. 2015, 57, 249-258. [CrossRef]

43. Yan, F.; Liu, L.; Zhang, Y.; Chen, M.; Chen, N. The research of dynamic variable fuzzy set assessment model in water quality evaluation. Water Resour. Manag. 2016, 30, 63-78. [CrossRef]

44. Li, B.; Yang, G.; Wan, R.; Hormann, G. Dynamic water quality evaluation based on fuzzy matter-element model and functional data analysis, a case study in Poyang Lake. Environ. Sci. Pollut. Res. Int. 2017, 24, 19138-19148. [CrossRef]

45. Aitchison, J. Principal component analysis of compositional data. Biometrika 1983, 70, 57-65. [CrossRef]

46. Diakoulaki, D.; Mavrotas, G.; Papayannakis, L. Determining objective weights in multiple criteria problems: The critic method. Comput. Oper. Res. 1995, 22, 763-770. [CrossRef]

47. Pu, Y.; Apel, D.; Xu, H. A principal component analysis/fuzzy comprehensive evaluation for rockburst potential in Kimberlite. Pure Appl. Geophys. 2018, 175, 2141-2151. [CrossRef]

48. Verma, R.; Suthar, S. Performance assessment of horizontal and vertical surface flow constructed wetland system in wastewater treatment using multivariate principal component analysis. Ecol. Eng. 2018, 116, 121-126. [CrossRef]

49. Alemi-Ardakani, M.; Milani, A.S.; Yannacopoulos, S.; Shokouhi, G. On the effect of subjective, objective and combinative weighting in multiple criteria decision making: A case study on impact optimization of composites. Expert Syst. Appl. 2016, 46, 426-438. [CrossRef]

50. Li, L.; Hang, J.; Sun, H.; Wang, L. A conjunctive multiple-criteria decision-making approach for cloud service supplier selection of manufacturing enterprise. Adv. Mech. Eng. 2017, 9, 1-15. [CrossRef]

51. Keshavarz Ghorabaee, M.; Amiri, M.; Zavadskas, E.K.; Antucheviciene, J. A new hybrid fuzzy MCDM approach for evaluation of construction equipment with sustainability considerations. Arch. Civ. Mech. Eng. 2018, 18, 32-49. [CrossRef]

52. Li, Z.; Yang, T.; Huang, C.; Xu, C.; Shao, Q.; Shi, P.; Wang, X.; Cui, T. An improved approach for water quality evaluation: TOPSIS-based informative weighting and ranking (TIWR) approach. Ecol. Indic. 2018, 89, 356-364. [CrossRef]

53. Rostamzadeh, R.; Keshavarz Ghorabaee, M.; Govindan, K.; Esmaeili, A.; Nobar, H.B.K. Evaluation of sustainable supply chain risk management using an integrated fuzzy TOPSIS-CRITIC approach. J. Clean. Prod. 2018, 175, 651-669. [CrossRef]

54. Smith, T.E. Estimation bias in spatial models with strongly connected weight matrices. Geogr. Anal. 2010, 41, 307-332. [CrossRef]

55. Stakhovych, S.; Bijmolt, T.H.A. Specification of spatial models: A simulation study on weights matrices. Pap. Reg. Sci. 2010, 88, 389-408. [CrossRef] 
56. Seya, H.; Yamagata, Y.; Tsutsumi, M. Automatic selection of a spatial weight matrix in spatial econometrics: Application to a spatial hedonic approach. Sci. Urban Econ. 2013, 43, 429-444. [CrossRef]

57. Rincke, J. Policy diffusion in space and time: The case of charter schools in California school districts. Sci. Urban Econ. 2007, 37, 526-541. [CrossRef]

58. Moscone, F.; Knapp, M.; Tosetti, E. Mental health expenditure in England: A spatial panel approach. J. Health Econ. 2007, 26, 842-864. [CrossRef]

59. Tong, T.; Yu, T.-H.E.; Cho, S.-H.; Jensen, K.; Ugarte, D.D.L.T. Evaluating the spatial spillover effects of transportation infrastructure on agricultural output across the united states. J. Transp. Geogr. 2013, 30, 47-55. [CrossRef]

60. Shi, W.; Lee, L.F. Spatial dynamic panel data models with interactive fixed effects. J. Econom. 2017, 197, 323-347. [CrossRef]

61. Lesage, J.P.; Ha, C.L. The impact of migration on social capital: Do migrants take their bowling balls with them? Growth Change 2012, 43, 1-26. [CrossRef]

62. Fingleton, B.; Palombi, S. Spatial panel data estimation, counterfactual predictions, and local economic resilience among British towns in the Victorian era. Sci. Urban Econ. 2013, 43, 649-660. [CrossRef]

63. Qu, X.; Lee, L.F.; Yu, J.H. QML estimation of spatial dynamic panel data models with endogenous time varying spatial weights matrices. J. Econom. 2017, 197, 173-201. [CrossRef]

64. Liao, C.; Yue, Y.; Wang, K.; Fensholt, R.; Tong, X.; Brandt, M. Ecological restoration enhances ecosystem health in the karst regions of southwest China. Ecol. Indic. 2018, 90, 416-425. [CrossRef]

65. Ullah, S.; Finch, C.F. Applications of functional data analysis: A systematic review. BMC Med. Res. Methodol. 2013, 13, 43. [CrossRef]

66. Chao, K.H.; Li, C.J. An intelligent maximum power point tracking method based on extension theory for PV systems. Expert Syst. Appl. 2010, 37, 1050-1055. [CrossRef]

67. Su, H.; Yang, M.; Wen, Z. Multi-layer multi-index comprehensive evaluation for dike safety. Water Resour. Manag. 2015, 29, 4683-4699. [CrossRef]

68. Zhong, D.; Wang, Z.; Zhang, Y.; Shi, M. Fluid-solid coupling based on a refined fractured rock model and stochastic parameters: A case study of the anti-sliding stability analysis of the Xiangjiaba project. Rock Mech. Rock Eng. 2018, 51, 2555-2567. [CrossRef]

69. Wu, Z.; Su, H. Dam health diagnosis and evaluation. Smart Mater. Struct. 2005, 14, S130-S136. [CrossRef] 